\title{
In vitro bioaccessibility, antioxidant and antibacterial activities of three different safflower (Carthamus tinctorius L.) genotypes
}

\author{
Kubra OZKAN ${ }^{1 *}$ (D), Hatice BEKIROGLU ${ }^{1}$ (iD), Yuksel BAYRAM ${ }^{2}$ (D), Osman SAGDIC ${ }^{1 D}$, Sabri ERBAS $^{3}$ (iD
}

\begin{abstract}
Safflower (Carthamus tinctorius L.) is one of the significant medicinal and aromatic plants and used as the source of food additives, natural dyestuffs, healthy beverages and cosmetics in various countries. In this study, extracts of three safflower genotypes (Remzibey-05, Dincer 5-18-1, and Arizona SC III) were prepared and examined for the first time in terms of their total phenolic content (TPC), antioxidant activities using radical scavenging capacity (DPPH) and copper reducing antioxidant capacity (CUPRAC) assays after subjecting them to in vitro gastrointestinal digestion. Additionally, the antibacterial potential of the flower extracts was determined. There were significant differences $(P<0.05)$ in antioxidant activities between the extracts of the different genotypes of safflower; the highest antioxidant activity was observed in Remzibey-05, while the phenolic content reached its maximum in Arizona SC III. After gastric digestion (PG), in comparison to the initial values, significantly lower recovery levels of TPC (5-8\%), DPPH (11-39\%) and CUPRAC (7-15\%) were observed for the safflower extracts. The highest inhibition zone was observed in the Dincer 5-18-1 extract applied against Listeria monocytogenes. The results showed that the extracts of the safflower genotypes displayed potent antioxidant and antibacterial activities, and the safflower extracts were important in terms of the bioaccessibility of bioactive compounds.
\end{abstract}

Keywords: Carthamus tinctorius L.; natural colorant; bioaccessibility; antioxidant activity; antibacterial activity.

Practical Application: Extracts of three safflower genotypes were prepared and subjected to an in vitro digestion process. Then, the colorimetric properties, total phenolic content, antioxidant and antibacterial activities of the extract samples obtained from the process were assessed.

\section{Introduction}

Safflower (Carthamus tinctorius L.), which belongs to the Compositae family, has been utilized traditionally for food coloring and as an additive for food, healthy beverages and cosmetics in many countries (Salem et al., 2014; Jia-Xi et al., 2019). A wide variety of glycosides has been isolated from the dried flowers of $C$. tinctorius used as a traditional medicinal plant (Zhang et al., 2019). C. tinctorius has been identified to consist of more than 200 compounds including flavonoids, alkaloids, lignans, alkane diols, riboflavin, steroids and quinochalcone C-glycosides (Li et al., 2017).

Flower petals contain three dyeing pigments: Safflower yellow A, safflower yellow B, and red (Carthamin). Compared to carthamin (red), large quantities of yellow pigments are present in safflower. Additionally, safflower yellow pigments are more stable than carthamin under ultraviolet (UV) light (Elshemy et al., 2019). In other words, the main active ingredients which can be extracted from dried petals of safflower could be stated as two main types. These are major red pigments named carthamin, which are water-insoluble, and major yellow pigments named hydroxysafflor yellow A and safflor yellow B, which are watersoluble (Jadhav \& Joshi, 2015). Thus, C. tinctorius is used as a dyestuff in the food and textile industry, and it is frequently used for adulteration instead of saffron (Villa et al., 2017). Moreover, synthetic dyes and antioxidants have wide use in the food industry. Consumer preferences have been directed towards natural dyes and antioxidants because of safety concerns and their helpful effects against certain diseases, such as neurodegenerative disorders, cancer, aging, diabetes and coronary heart disease (Karimkhani et al., 2016). Thus, natural colorants from plant pigments are being explored and analyzed as alternatives or replacements for synthetic food colorants. In general, consumers are concerned about the safety of foods that contain synthetic ingredients. Safflower is safe for use in foods and has a wide range of biological activities including antioxidant, antimicrobial (Salem et al., 2011), anti-anxiety, antidepressant (Qazi et al., 2015), anticoagulant (Wang et al., 2014), antitumor (Luo et al., 2015) and anti-osteoporosis (Choi et al., 2010) effects.

When medicinal plants and their phenolic extracts are consumed, they undergo a digestive process in the intestines. In vitro digestion models are considered to be simple, fast, inexpensive, safe and repeatable tools to evaluate the digestive stability of diverse food components and have been improved as another approach to in vivo studies. They also do not have the same ethical restrictions as many in vivo methods (Gunathilake et al., 2018). Therefore, it is significant to determine how the digestive process affects the stability and antioxidant activities of phenolic compounds. 
There have been some studies in the literature about the determination of antioxidant and antimicrobial effects, as well as bioactive compounds, in extracts of different safflower genotypes (Hiramatsu et al., 2009; Wu et al., 2013; Salem et al., 2014; Karimkhani et al., 2016). Furthermore, even though many studies have been reported on the properties of edible flowers, there are few data about their bioactive compounds measured by in vitro digestion methods (Chen et al., 2015). Additionally, to our knowledge, there has been no study focused on the antioxidant potential of safflower genotype extracts through the in vitro gastrointestinal digestion process. Therefore, in this study, extracts of three safflower genotypes were prepared and subjected to an in vitro digestion process. Then, the total phenolic content and antioxidant activities of the extract samples obtained from the process were assessed. Additionally, the antibacterial activity of the three safflower genotype extracts and the colorimetric properties of the safflower genotype flowers were evaluated.

\section{Materials and methods}

\subsection{Chemicals and reagents}

Aluminum trichloride, sodium nitrite, sodium carbonate, Folin-Ciocalteu's phenol reagent, ammonium acetate, copper(II) chloride, sodium bicarbonate, ethanol, hydrochloric acid (37\%), sodium hydroxide, nutrient broth and nutrient agar were supplied by Merck (Darmstadt, Germany), and gallic acid, 2,2-Diphenyl1-picrylhydrazyl (DPPH), ( \pm )-6- Hydroxy-2,5,7,8-tetramethylchromane-2-carboxylic acid (Trolox), catechin and neocuproine were supplied by Sigma-Aldrich (Steinheim, Germany). Pepsin from porcine gastric mucosa (Merck, EC 3.4.23.1), pancreatin from porcine pancreas (Sigma-Aldrich, 8xUSP specification) and all other reagents were used to prepare simulated gastric and intestinal fluids.

\subsection{Plant materials}

In the study, three safflower genotypes as Remzibey-05 (orange flower), Dincer 5-18-1 (red flower) and Arizona SC III (yellow flower) were used as the plant material. These genotypes were grown in a trial area located at the Department of Field Crops, Faculty of Agriculture, Isparta University of Applied Sciences, Isparta (longitude 30³3' E, latitude 37²47’ N, elevation $997 \mathrm{~m}$ ) under the soil and climatic conditions in 2016. The soil properties of the trial area were assessed according to the method proposed by Rowell (1996) and reported based on the results in a previous study (Erbas et al., 2016). The experiments were not irrigated. Weed control was performed manually and by mechanical rotary tillage. The climatic data for the experimental area are presented in Table 1 . The flowers of the varieties were harvested in the first week of July by hand. After this, the samples were dried in shadow at room temperature $\left(25 \pm 2{ }^{\circ} \mathrm{C}\right)$ until reaching a constant weight. The safflower genotypes were kept in a dark place at $20 \pm 2{ }^{\circ} \mathrm{C}$ until the time of the analysis.

When the climate data are analyzed, there were no very high or low temperatures and precipitation during the vegetation period (March-July) that would seriously affect the normal growth and development of the plants.

\subsection{Extraction of dried safflower genotypes}

The dried flowers of the safflower genotypes were ground into powders with a grinder. $50 \mathrm{~mL}$ of $50 \%$ aqueous ethanol (v:v) was added to $1.0 \mathrm{~g}$ of the powder, and then, the samples were placed on a magnetic stirrer at $25^{\circ} \mathrm{C}$ for 2.5 hours. The mixture was centrifuged at $2700 \mathrm{~g}$ and $4{ }^{\circ} \mathrm{C}$, and the supernatants were collected. This procedure was repeated with a pellet, and the supernatants were pooled. The combined supernatants were evaporated to dryness by a rotary evaporator at $40{ }^{\circ} \mathrm{C}$ under vacuum, reconstituted to $10 \mathrm{~mL}$ with deionized water and stored at $-20{ }^{\circ} \mathrm{C}$ for further analysis.

\subsection{Total Phenolic Content (TPC) assay}

According to the protocol described by Singleton et al. (1999), $0.5 \mathrm{~mL}$ of the safflower genotype extracts, $2.5 \mathrm{~mL}$ of the FC reagent $(0.2 \mathrm{~N})$ and $2 \mathrm{~mL}$ of a solution of $2 \%(\mathrm{w} / \mathrm{v}) \mathrm{Na}_{2} \mathrm{CO}_{3}$ were mixed. The samples were then incubated in a dark place at $25^{\circ} \mathrm{C}$ for $30 \mathrm{~min}$, and the absorbance values were detected using a spectrophotometer (Shimadzu 150 UV-1800 spectrophotometer, Japan) at $760 \mathrm{~nm}$. The results are presented in terms of mg gallic acid equivalent (GAE) per g dry flower with a linear range of $0.01-0.1 \mathrm{mg} / \mathrm{mL}\left(\mathrm{r}^{2}=0.993\right)$.

\subsection{Antioxidant activity assays}

The scavenging activity of the safflower genotype extracts against DPPH was detected by a spectrophotometer (SánchezMoreno, 2002; Singh et al., 2002). Absorbance was measured by a spectrophotometer at $517 \mathrm{~nm}$. The results were calculated and are presented as mg Trolox equivalent (TE) per g dry flower with a linear range of $0.05-0.5 \mathrm{mg} / \mathrm{mL}\left(\mathrm{r}^{2}=0.996\right)$.

According to the protocol described by Apak et al. (2004), the CUPRAC of the safflower genotype extracts was determined. Absorbance was measured at $450 \mathrm{~nm}$ using a spectrophotometer. The results are given as mg Trolox equivalent (TE) per g dry flower with a linear range of $0.05-1 \mathrm{mg} / \mathrm{mL}\left(\mathrm{r}^{2}=0.991\right)$.

Table 1. The climate data of Isparta for long years and 2016.

\begin{tabular}{|c|c|c|c|c|c|c|}
\hline \multirow{2}{*}{ Month } & \multicolumn{2}{|c|}{ Total Precipitation, $\mathrm{L} \mathrm{m}^{2}$} & \multicolumn{2}{|c|}{ Mean temperature, ${ }^{\circ} \mathrm{C}$} & \multicolumn{2}{|c|}{ Mean humidity, \% } \\
\hline & $1950-2016$ & 2016 & $1950-2016$ & 2016 & $1950-2016$ & 2016 \\
\hline March & 55.3 & 111.6 & 6.2 & 6.7 & 65.3 & 64.8 \\
\hline April & 55.3 & 26.1 & 10.8 & 9.0 & 61.0 & 58.2 \\
\hline May & 52.3 & 67.5 & 15.6 & 16.6 & 57.4 & 51.8 \\
\hline Jun & 30.6 & 92.2 & 20.2 & 18.3 & 51.2 & 63.5 \\
\hline July & 14.6 & 3.0 & 23.7 & 24.2 & 45.3 & 43.9 \\
\hline
\end{tabular}




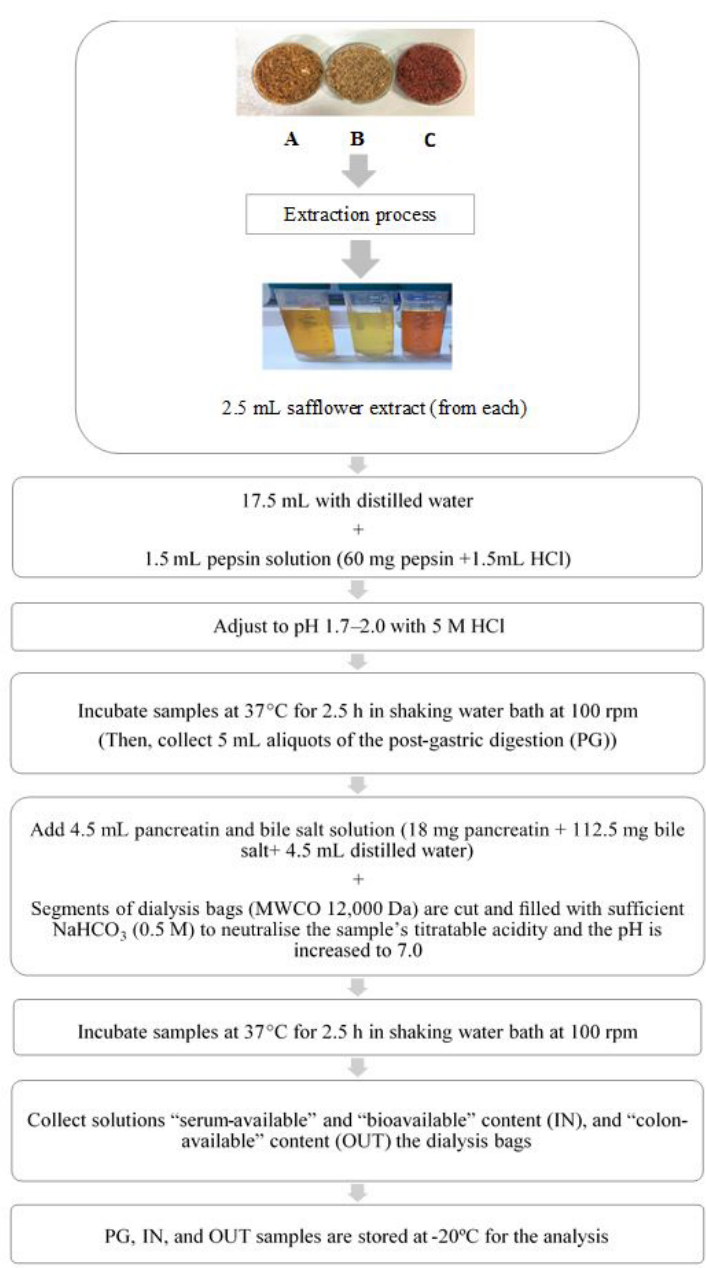

Figure 1. Flow chart outlining the steps involved in the in vitro gastrointestinal digestion procedure. (A) Remzibey-05; (B) Arizona SC III; (C) Dincer 5-18-1; dried flowers of the safflower genotypes.

\subsection{In vitro digestion assay}

The digestion procedure was applied by following the methods described by McDougall et al. (2005) and Kamiloglu et al. (2014). The change in the antioxidant activity and release of polyphenolics of the safflower genotype extracts were examined at a gastric stage and an intestinal stage of digestion, and the in vitro gastrointestinal digestion procedure is shown in Figure 1. The blank was prepared with the same chemicals, without a sample and subjected to the same conditions. Then, the sample taken at each digestion step was centrifuged at $2700 \mathrm{xg}$ for $10 \mathrm{~min}$ and stored at $-20^{\circ} \mathrm{C}$ for the analysis. Total phenolic contents (TPC) and antioxidant capacities were detected for each of these post-gastric (PG), "serum-available" and "bioavailable" content (IN) and "colon-available" content (OUT) samples using the methods described above.

\subsection{Color analyses}

The color of the safflower genotype flowers was determined with a chromameter (CR-400, Konica Minolta, Tokyo, Japan), and each sample was analyzed in triplicates. Before color analysis, calibration was performed using a white surface equipped with a $50-\mathrm{mm}$ aperture. The color was directly measured on the surface of the dried safflower flowers at room temperature. The color values of samples are expressed as $L *$ (lightness), $a *$ (redness) and $b *$ (yellowness) values indicated in the CIE system.

\subsection{Antibacterial activity assays}

The antibacterial activity of the safflower genotype extracts was determined by using the agar diffusion method against Gram-positive bacteria (Bacillus cereus FMC 19, Listeria monocytogenes ATCC 19118, Staphylococcus aureus ATCC 25923) and Gram-negative bacteria (Escherichia coli O157: H7 ATCC 33150, Salmonella Typhimurium ATCC 14028). Bacteria were inoculated in nutrient broth and incubated at $37^{\circ} \mathrm{C}$ for $24 \mathrm{~h}$. Then, $1 \%$ of the bacteria were added into the nutrient broth and re-incubated for $18 \mathrm{~h}$. The microbial cultures (1\%) were pipetted, sowed by the spread plate method and left for $20 \mathrm{~min}$. Then, 4 equidistant wells were bored by sterile cork borers $(\varnothing=5 \mathrm{~mm}$ ) (Sagdic et al., 2013). The safflower genotype extracts were dissolved in the solvent (water) as a final concentration of $10 \%$ (w:v), and $20 \mu \mathrm{L}$ of the safflower extract and blank (water) solutions was applied to the wells. Plates were incubated for bacteria at $37^{\circ} \mathrm{C}$, and the diameters of the inhibition zone $(\mathrm{mm})$ were then detected after 18-24 h.

\subsection{Statistical analysis}

The statistical analysis was carried out by means of SPSS Statistics (IBM SPSS 17.0, USA). All analyses were conducted in triplicates. The results are stated as mean \pm standard error. The significant differences between the extracts were determined via Duncan's multiple comparison tests in a $95 \%$ confidence interval when the one-way analysis of variance (ANOVA) result was significant.

\section{Results and discussion}

The changes in the total phenolic content and its quantities during the digestion of the safflower samples are presented in Table 2. The total phenolic content (TPC) of the safflower genotypes, Remzibey-05, Dincer 5-18-1 and Arizona SC III, was initially found at $21.39,18.01$ and $31.49 \mathrm{mg} \mathrm{GAE} / \mathrm{g}$ dry flower, respectively. The antioxidant activity of the samples was detected using two different methods, namely DPPH and CUPRAC, and the results showed the different tendencies over these two different methods. In terms of their antioxidant activity results, the safflower extracts ranged from 5.33 to $14.11 \mathrm{mg} \mathrm{TE} / \mathrm{g}$ dry flower for the DPPH assay and 49.90 to $95.60 \mathrm{mg}$ TE/g dry flower for the CUPRAC assay (Table 2). In the phase dialyzed after intestinal digestion (IN), the TPC value was found to be significantly lower than the initial value. In Table 2 , the recovery $\%$ of TPC and the antioxidant activities of the digested extracts are given at each step. After stomach digestion (PG), the material entered the IN fraction, and the material remained in the OUT fraction after intestinal digestion. The recovery (\%) of TPC and antioxidant activity values were measured by dividing the values obtained for the PG, IN and OUT fractions by the initial values, and then, stated as percentages. For a better evaluation of the change, the initial values are presented as $100 \%$. After gastric digestion (PG), in comparison to the initial values, a significantly 
Table 2. Changes in total phenolic content (TPC), and antioxidant activity (determined by DPPH and CUPRAC assays) of the safflower genotype extracts during in vitro gastrointestinal digestion.

\begin{tabular}{|c|c|c|c|c|c|}
\hline Analysis & Initial & PG & IN & OUT & Recovery (\%) \\
\hline \multicolumn{6}{|c|}{ TPC } \\
\hline Remzibey-05 & $21.39 \pm 0.50^{\mathrm{b}}$ & $3.07 \pm 0.01^{\mathrm{a}}$ & $1.27 \pm 0.06^{\mathrm{a}}$ & $1.76 \pm 0.03^{\mathrm{a}}$ & $6^{\mathrm{b}}$ \\
\hline Dincer 5-18-1 & $18.01 \pm 0.68^{\mathrm{a}}$ & $3.00 \pm 0.11^{\mathrm{a}}$ & $1.43 \pm 0.03^{\mathrm{ab}}$ & $2.01 \pm 0.04^{c}$ & $8^{c}$ \\
\hline Arizona SC III & $31.49 \pm 0.38^{c}$ & $3.56 \pm 0.01^{b}$ & $1.67 \pm 0.19^{\mathrm{b}}$ & $1.82 \pm 0.01^{\mathrm{b}}$ & $5^{\mathrm{a}}$ \\
\hline \multicolumn{6}{|c|}{ DPPH } \\
\hline Remzibey-05 & $14.11 \pm 0.38^{c}$ & $0.55 \pm 0.17^{b}$ & $1.63 \pm 1.10^{\mathrm{a}}$ & $2.69 \pm 0.09^{\mathrm{a}}$ & $11^{\mathrm{a}}$ \\
\hline Dincer 5-18-1 & $10.46 \pm 0.28^{\mathrm{b}}$ & $1.73 \pm 0.05^{\mathrm{c}}$ & $2.61 \pm 0.05^{\mathrm{a}}$ & $3.37 \pm 0.21^{\mathrm{b}}$ & $29^{\mathrm{b}}$ \\
\hline Arizona SC III & $5.33 \pm 0.09^{\mathrm{a}}$ & $0.29 \pm 0.11^{\mathrm{a}}$ & $2.12 \pm 0.08^{\mathrm{a}}$ & $3.25 \pm 0.08^{\mathrm{b}}$ & $39^{c}$ \\
\hline \multicolumn{6}{|c|}{ CUPRAC } \\
\hline Remzibey-05 & $95.60 \pm 2.83^{\mathrm{c}}$ & $8.24 \pm 0.04^{\mathrm{a}}$ & $6.70 \pm 0.90^{\mathrm{a}}$ & $9.39 \pm 0.32^{\mathrm{b}}$ & $7^{\mathrm{a}}$ \\
\hline Dincer 5-18-1 & $69.52 \pm 0.89^{b}$ & $10.06 \pm 0.87^{\mathrm{b}}$ & $9.34 \pm 0.07^{\mathrm{b}}$ & $6.90 \pm 0.92^{\mathrm{a}}$ & $14^{\mathrm{b}}$ \\
\hline Arizona SC III & $49.90 \pm 2.29^{\mathrm{a}}$ & $7.49 \pm 0.61^{\mathrm{a}}$ & $7.41 \pm 0.93^{\mathrm{a}}$ & $7.03 \pm 0.71^{\mathrm{a}}$ & $15^{\mathrm{c}}$ \\
\hline
\end{tabular}

Recovery (\%) of TPC and antioxidant activity values were calculated by dividing the values obtained for the IN fraction to the initial values and then stated as a percentage; PG (postgastric), recovered after gastric digestion; IN, dialyzed fraction; OUT, non-dialyzed fraction recovered after intestinal digestion. Data represent the average values \pm standard error of four independent samples. Different letters in the column represent significant differences $(P<0.05)$ for each assay, individually. TPC expressed in mg GAE/g dry flower, DPPH and CUPRAC expressed in mg TE per/g dry flower.

lower amount of TPC (14.40, 16.85 and 11.30\%) was received from the extract of Remzibey-05, Dincer 5-18-1 and Arizona SC III, respectively $(P<0.05)$. A similar trend was observed for the antioxidant activity results, where the recovery (\%) values obtained after PG were significantly lower $(P<0.05)$ in comparison to the initial values.

Salem et al. (2011) showed that extraction with $2 \%$ aqueous acetone (v:v) had the highest flower polyphenolic content in Carthamus tinctorius L. (15.09 mg GAE/g dry weight). Baydar \& Özkan (2005) reported that the TPC values in petals of the safflower cultivars 'Dinçer,' 'Yenice' and '5-154' in 80\% aqueous methanol (v:v) were 9.06, 20.92 and 16.62mg GAE/g dry matter, respectively. In a study by Karimkhani et al. (2016), the TPC and antioxidant capacity of the methanolic extracts of four different safflower cultivars were examined, and the values varied from 46.2 to $62.3 \mathrm{mg}$ GAE/g dry matter. TPC results determined in their study were higher than those in our study. The differences in the results may be explained by differences in the type of extraction solvent, extraction conditions, as well as plant varieties. In the study by Hiramatsu et al. (2009), carthamin was detected in the petals of Carthamus tinctorius Linne. The carthamin content was lower in the yellow petals than that of the orange petals in safflower, and not detectable in the white petals of safflower. They also reported that this content was correlated with DPPH radical scavenging activity. Similarly, in our study, the antioxidant value of the Remzibey- 05 extract (orange petals) also exhibited higher antioxidant values than those of the Arizona SC III extract (yellow petals). Moreover, in our study, the results on the antioxidant activity values measured by the CUPRAC method were higher with respect to the DPPH method. This observation might be related to the fact that, while DPPH uses a radical dissolved solely in the organic solvent and therefore applies to hydrophobic systems, the CUPRAC assay may measure both the lipophilic and hydrophilic antioxidant activity of the extracts since the reagent is soluble in both aqueous and organic solvents (Capanoglu et al., 2018).
Güneş et al. (2019) determined the phenolic contents of some varieties of the Asteraceae family (Artemisia vulgaris, Echinacea purpurea, Carthamus tinctorius, Helianthus annuus, Centaurea cyanus). The highest amount was found to be in E. purpurea (13.34 mg GAE/g FW), and the lowest amount of total phenolic contents were observed to be in $H$. annuus $(2.65 \mathrm{mg}$ GAE/g FW), whereas the TPC of Carthamus tinctorius was found as $7.04 \mathrm{mg} \mathrm{GAE} / \mathrm{g}$ FW. In their study, the TPC of C. tinctorius had a similar result to that in our study.

After intestinal digestion, the recovery (\%) for the TPC of the 'IN' fractions was significantly lower than 'PG' for the extracts of Remzibey-05, Dincer 5-18-1 and Arizona SC III (5.94, 8.09 and $5.30 \%$ respectively). Similarly, the antioxidant activity decreased in the 'IN' samples, and for the safflower extracts (determined by the CUPRAC method), the recovery (\%) values were between 7.02 and $14.85 \%$, compared to the values obtained at the 'PG' step. In contrast, in the 'IN' fraction of the safflower ethanolic extracts, the recovery (\%) values ranged from 11.55 to 39.70 for the DPPH assay and increased in comparison to the PG fraction. Because of the fact that they remove several types of free radicals such as DPPH, safflower compounds have an antioxidant capacity, which shows the significance of safflower as a source of antioxidants (Ibrahim et al., 2019).

For all samples, the TPC recoveries of the 'OUT' fractions were significantly higher than those of the 'IN' fractions. Similarly, to the outcomes of TPC, for all samples, the recovery values of antioxidant activity (determined by the DPPH method) obtained for the OUT fractions were higher than those of the IN fractions. A similar trend was described by Gunathilake et al. (2018) who determined the effect of simulated gastrointestinal digestion of Gymnema lactiferum, Cassia auriculata, Olax zeylanica, Centella asiatica, Passiflora edulis and Sesbania grandiflora on the stability and recovery of total polyphenol contents. After gastric digestion, the recovery percentage of TPC in fresh green leafy vegetables was in the range of $13.9-71.8 \%$ in comparison to the TPC of the methanolic extracts of the leafy vegetables tested. The TPC 
recoveries dialysable polyphenols (IN fraction) were also found to range between $3.06 \%$ and $12.30 \%$ after intestinal digestion.

Chen et al. (2015) determined the stability of TPC and antioxidant activity of different edible flowers selected with an in vitro digestive model. It was identified that the $\mathrm{DPPH}$ values of edible flowers increased except for one edible flower after the gastric phase of digestion. The TPC of all samples decreased in comparison to the initial TPC, while the TPC of 6 samples increased after the duodenum stage of digestion. The authors also reported that, after the gastric phase of digestion, the DPPH values of all of edible flowers increased in comparison to the duodenal phase of digestion. In our study, the DPPH values of all safflower samples increased in comparison to the gastric phase of digestion, after the intestinal phase (IN+OUT) of digestion.

Previous studies have shown that antioxidants can be degraded by alkaline $\mathrm{pH}$ after the pancreatic digestion phase. Thus, when exposed to such conditions, it is possible to convert some of polyphenols into different structural forms with different biological activity, bioavailability, bioaccessibility and different chemical properties (Chen et al., 2015).

The mean color values of the safflower genotypes were obtained by measuring the $L^{*}, a^{*}$, and $b^{*}$ chromatic parameters as shown in Table 3. The $L^{*}, a^{*}$ and $b^{*}$ values were in the ranges of 49.63-67.35, 4.69-25.19 and 21.05-30.71, respectively, for the safflower samples. In Dincer 5-18-1, the redness $\left(a^{*}\right)$ value increased in the surfaces, and the difference was significant compared to Remzibey-05 and Arizona SC III, whereas in Remzibey-05, the yellowness $\left(b^{*}\right)$ value increased in the surfaces, and the difference was significant compared to Arizona SC III and Dincer 5-18-1.

Safflower, which has saffron-like color pigments, is used in some provinces in southeast Turkey to provide a golden yellow color to the rice. Remzibey-05 (orange), one of the safflower genotypes, has been found to have values closer to saffron color properties when examined in terms of color values. Therefore, it may be considered as a lower-cost natural colorant that can be preferred instead of saffron used to color rice.
Pu et al. (2019) aimed to make a comprehensive assessment of safflowers in different production areas using biological and color analysis. All safflower samples were classified in class I and class II based on color measurements. The ranges of the $L^{*}, a^{*}$ and $b^{*}$ values in the safflower samples were 30.9-53.5, 19.6-34.5 and 25.9-55.6, respectively. Thus, the authors suggested that safflowers classified into class I were brighter, redder, more yellow, more orange-yellow and more vivid to the eye than class II. In our study, a similar trend was found for the $L^{*}(49.63)$, $a^{*}(25.19)$ and $b^{*}$ (21.05) values of Dincer 5-18-1, one of the safflower genotypes.

In a study conducted about sausages, it was found that safflower provided the desired cooking redness without nitrite, and the presence of nitrite also inhibited lipid oxidation and reduced residual nitrite content. Safflower may be used as a natural colorant to provide the desired cooking redness in meat products, especially in sausages due to its main color ingredient carthamin (Kim et al., 2015). The red color values of Arizona SC III and Dincer 5-18-1, two of the safflower genotypes, in our study were in parallel with those in the aforementioned study. Although carthamin has limited usage in the food industry due to its low water solubility, it is used for chocolate production in countries such as Japan and China (Ekin, 2005; Emongor, 2010). In similarity to these studies, safflower may be recommended to be used as a color additive in other foodstuffs to obtain red, orange and yellow colors as well as providing a natural antioxidant effect.

The antibacterial activities of the extracts of 3 safflower genotypes are given in Table 4 . These ethanolic extracts showed satisfying antibacterial effects. All safflower extracts affected Staphylococcus aureus ATCC 25923 and Bacillus cereus FMC19. The highest inhibition zone was observed in the Dincer 5-18-1 extract applied against Listeria monocytogenes ATCC 19118. Among the extracts of the 3 safflower genotypes, the differences in inhibition against Bacillus cereus and Escherichia coli O157:H7 were significant $(P<0.05)$, while between the Dincer 5-18-1 and Arizona SC III extracts, the differences in inhibition

Table 3. Color measurements of safflower genotypes.

\begin{tabular}{ccrr}
\hline \multirow{2}{*}{ Safflower Genotypes } & \multicolumn{3}{c}{ Color parameters } \\
\cline { 2 - 4 } & $\boldsymbol{L}^{\star}$ & $\boldsymbol{a}^{\star}$ & $\boldsymbol{b}^{\star}$ \\
\hline Remzibey-05 & $57.92 \pm 0.83^{\mathrm{b}}$ & $8.17 \pm 0.15^{\mathrm{b}}$ & $30.71 \pm 0.54^{\mathrm{a}}$ \\
Dincer 5-18-1 & $49.63 \pm 0.49^{\mathrm{c}}$ & $25.19 \pm 0.41^{\mathrm{a}}$ & $21.05 \pm 0.63^{\mathrm{c}}$ \\
Arizona SC III & $67.35 \pm 0.54^{\mathrm{a}}$ & $4.69 \pm 0.23^{\mathrm{c}}$ & $23.17 \pm 0.48^{\mathrm{b}}$ \\
\hline
\end{tabular}

Means with different letters in the same column are significantly different $(P<0.05)$ Duncan's multiple range test.

Table 4. Antibacterial effect of the safflower genotype extracts.

\begin{tabular}{ccccc}
\hline \multirow{2}{*}{ Bacteria } & \multirow{2}{*}{ Negative control (Water) } & \multicolumn{3}{c}{ Safflower extracts } \\
\cline { 3 - 5 } & & Remzibey-05 & Dincer 5-18-1 & Arizona SC III \\
\hline Bacillus cereus & $n z$ & $7.00 \pm 0.50^{\mathrm{ab}}$ & $7.83 \pm 0.76^{\mathrm{b}}$ & $6.50 \pm 0.50^{\mathrm{a}}$ \\
Staphylococcus aureus & & $8.50 \pm 1.32^{\mathrm{a}}$ & $10.50 \pm 0.50^{\mathrm{b}}$ & $10.50 \pm 0.50^{\mathrm{b}}$ \\
Listeria monocytogenes & $n z$ & $11.00 \pm 1.00^{\mathrm{a}}$ & $n z$ \\
S. Typhimurium & & $9.50 \pm 0.50^{\mathrm{a}}$ & $n z$ & $n z$ \\
Escherichia coli O157: H7 & $n z$ & $8.33 \pm 0.57^{\mathrm{b}}$ & $6.83 \pm 0.76^{\mathrm{a}}$ \\
\hline
\end{tabular}

Inhibition zone in diameter $(\mathrm{mm})$. Means with different letters in the same row are significantly different $(P<0.05)$ Duncan's multiple range test. $n z$ : no inhibition zone. 
against $S$. aureus ATCC 25923 were not significant $(P>0.05)$. Therefore, it was determined that the different genotypes of the safflower plant were also effective on its antibacterial activity.

Salem et al. (2014) found the antibacterial effects of precarthamin, carthamin isolated from C. tinctorius flowers during flowering, and these flowers were tested by cutting them in $6 \mathrm{~mm}$ in diameter and applying their extracts in wells against three Gram-positive bacteria (E. coli, B. cereus, and S. aureus). The authors reported that carthamin had a relatively strong antibacterial effect (the inhibition zone reached up to $26 \mathrm{~mm}$ against $E$. coli) against the various bacterial strains during the flower stages, while precarthamin had the least antibacterial effect against the selected bacterial strains (the inhibition zone did not exceed $17.56 \mathrm{~mm}$ ). In our study, with the ethanolic extracts of safflower, lower inhibition zones were obtained, as $8.50-10.50 \mathrm{~mm}$ and $6.83-8.33 \mathrm{~mm}$ against $S$. aureus and E. coli, respectively. In another study, the antibacterial effects of safflower seed meal extract were determined using a disc diffusion test against the diffusion assay of four pathogenic bacteria. The inhibition zone diameters of L. monocytogenes, S. Typhimurium, E. coli O157:H7 and S. aureus were 15.91, 12.36, 11.97 and $15.33 \mathrm{~mm}$, respectively. Safflower seed kernel extract was reported to have an antimicrobial effect against $L$. monocytogenes (Son et al., 2017). Similarly, in our study, it may be stated that the safflower extract had a high inhibition zone against L. monocytogenes.

Ibrahim et al. (2019) showed the antibacterial activity (for S. aureus) of safflower and Rhus extracts and their synthesized nanoparticles (iron, silver, copper, and zinc nanoparticles). The antibacterial activities of safflower extracts and their synthesized nanoparticles were found as 7.60-16.80 $\mathrm{mm}$, while the antibacterial activities of Rhus extracts and their synthesized nanoparticles were found as $0.0-8.50 \mathrm{~mm}$. What is more, the highest antibacterial activity was in the case of the iron nanoparticles from safflower against $S$. aureus with an inhibition zone of $16.8 \mathrm{~mm}$.

\section{Conclusions}

It could be stated that this study reported for the first time the in vitro bioaccessibility of antioxidant activity and change of phenolic compounds in three safflower genotypes. When the safflower genotypes were submitted to in vitro gastrointestinal digestion in the form of the extracts, the percentage recovery values of TPC and antioxidant activities varied significantly. The safflower extracts also showed valuable antibacterial activity. Further studies may include the determination of individual phenolics in safflower genotype extracts depending on the method of preparation by organic solvent extraction, as well as how the composition of the extract would affect their stability during in vitro digestion. Therefore, safflower genotypes might be used to explore novel natural antioxidant and antimicrobial food ingredients, and extracts obtained from safflower genotypes might be used as a color additive in other foodstuffs to obtain red, orange and yellow colors.

\section{References}

Apak, R., Güçlü, K., Özyürek, M., \& Karademir, S. E. (2004). Novel total antioxidant capacity index for dietary polyphenols and vitamins $\mathrm{C}$ and $\mathrm{E}$, using their cupric ion reducing capability in the presence of neocuproine: CUPRAC method. Journal of Agricultural and Food Chemistry, 52(26), 7970-7981. http://dx.doi.org/10.1021/jf048741x. PMid:15612784.

Baydar, H., \& Özkan, G. (2005). Antioxidant activities of safflower (Carthamus tinctorius L.) petal extracts. In Proceedings of the VI International Safflower Conference. SAFFLOWER: a Unique Crop for Oil Spices and Health Consequently, a Better Life for You (pp. 4-314). İstanbul: Engin Maatbacilik Ltd.

Capanoglu, E., Kamiloglu, S., Ozkan, G., \& Apak, R. (2018). Evaluation of antioxidant activity/capacity measurement methods for food products. In R. Apak, E. Capanoglu \& F. Shahidi (Eds.), Measurement of antioxidant activity and capacity: recent trends and applications (pp. 273-286). Chicester: John Wiley \& Sons. http://dx.doi. org/10.1002/9781119135388.ch13.

Chen, G. L., Chen, S. G., Xie, Y. Q., Chen, F., Zhao, Y. Y., Luo, C. X., \& Gao, Y. Q. (2015). Total phenolic, flavonoid and antioxidant activity of 23 edible flowers subjected to in vitro digestion. Journal of Functional Foods, 17, 243-259. http://dx.doi.org/10.1016/j.jff.2015.05.028.

Choi, E. M., Kim, G. H., \& Lee, Y. S. (2010). Carthamus tinctorius flower extract prevents $\mathrm{H}_{2} \mathrm{O}_{2}$-induced dysfunction and oxidative damage in osteoblastic MC3T3-E1 cells. Phytotherapy Research, 24(7), 10371041. http://dx.doi.org/10.1002/ptr.3070. PMid:19960423.

Ekin, Z. (2005). Resurgence of safflower (Carthamus tinctorius L.) utilization: a global view. Journal of Agronomy, 4(2), 83-87. http:// dx.doi.org/10.3923/ja.2005.83.87.

Elshemy, N., Megaly, M., Haggag, K., \& Hashem, A. (2019). Development and optimization of a non-traditional extraction process of yellow colorant from safflower petals as a natural colorant. Egyptian Journal of Chemistry, 62(2), 231-245. http://dx.doi.org/10.21608/ ejchem.2018.5119.1453.

Emongor, V. (2010). Safflower (Carthamus tinctorius L.) the underutilized and neglected crop: a review. Asian Journal of Plant Sciences, 9(6), 299-306. http://dx.doi.org/10.3923/ajps.2010.299.306.

Erbas, S., Tonguc, M., \& Sanli, A. (2016). Variations in the agronomic and quality characteristics of domestic and foreign safflower (Carthamus tinctorius L.) genotypes. Turkish Journal of Field Crops, 21(1), 110-119. http://dx.doi.org/10.17557/tjfc.56268.

Gunathilake, K. D. P. P., Ranaweera, K. K. D. S., \& Rupasinghe, H. P. V. (2018). Change of phenolics, carotenoids, and antioxidant capacity following simulated gastrointestinal digestion and dialysis of selected edible green leaves. Food Chemistry, 245, 371-379. http://dx.doi. org/10.1016/j.foodchem.2017.10.096. PMid:29287383.

Güneş, A., Kordali, Ş., Turan, M., \& Usanmaz Bozhüyük, A. U. (2019). Determination of antioxidant enzyme activity and phenolic contents of some species of the Asteraceae family from medicinal plants. Industrial Crops and Products, 137, 208-213. http://dx.doi. org/10.1016/j.indcrop.2019.05.042.

Hiramatsu, M., Takahashi, T., Komatsu, M., Kido, T., \& Kasahara, Y. (2009). Antioxidant and neuroprotective activities of Mogamibenibana (safflower, Carthamus tinctorius Linne). Neurochemical Research, 34(4), 795-805. http://dx.doi.org/10.1007/s11064-0089884-5. PMid:19082884. 
Ibrahim, F. Y., El-Khateeb, A. Y., \& Mohamed, A. H. (2019). Rhus and safflower extracts as potential novel food antioxidant, anticancer, and antimicrobial agents using nanotechnology. Foods, 8(4), 139. http://dx.doi.org/10.3390/foods8040139. PMid:31018544.

Jadhav, B. A., \& Joshi, A. A. (2015). Extraction and quantitative estimation of bioactive components (yellow and red carthamin) from dried safflower petals. Indian Journal of Science and Technology, 8(16), 1-5. http://dx.doi.org/10.17485/ijst/2015/v8i16/42380.

Jia-Xi, L., Chun-Xia, Z., Ying, H., Meng-Han, Z., Ya-Nan, W., YueXin, Q., Jing, Y., Wen-Zhi, Y., Miao-Miao, J., \& De-An, G. (2019). Application of multiple chemical and biological approaches for quality assessment of Carthamus tinctorius L. (safflower) by determining both the primary and secondary metabolites. Phytomedicine, 58, 152826. http://dx.doi.org/10.1016/j.phymed.2019.152826. PMid:30836217.

Kamiloglu, S., Pasli, A. A., Ozcelik, B., \& Capanoglu, E. (2014). Evaluating the in vitro bioaccessibility of phenolics and antioxidant activity during consumption of dried fruits with nuts. LebensmittelWissenschaft + Technologie, 56(2), 284-289. http://dx.doi.org/10.1016/j. lwt.2013.11.040.

Karimkhani, M. M., Shaddel, R., Khodaparast, M. H. H., Vazirian, M., \& Piri-Gheshlaghi, S. (2016). Antioxidant and antibacterial activity of safflower (Carthamus tinctorius L.) extract from four different cultivars. Quality Assurance and Safety of Crops \& Foods, 8(4), 565574. http://dx.doi.org/10.3920/QAS2015.0676.

Kim, H. W., Hwang, K. E., Song, D. H., Kim, Y. J., Ham, Y. K., Lim, Y. B., Jeong, T.-J., Choi, Y.-S., \& Kim, C.-J. (2015). Wheat fiber colored with a safflower (Carthamus tinctorius L.) red pigment as a natural colorant and antioxidant in cooked sausages. LebensmittelWissenschaft + Technologie, 64(1), 350-355. http://dx.doi.org/10.1016/j. lwt.2015.05.064.

Li, F., He, Z., \& Ye, Y. (2017). Isocartormin, a novel quinochalcone C-glycoside from Carthamus tinctorius. Acta Pharmaceutica Sinica. B, 7(4), 527-531. http://dx.doi.org/10.1016/j.apsb.2017.04.005. PMid:28752041.

Luo, Z., Zeng, H., Ye, Y., Liu, L., Li, S., Zhang, J., \& Luo, R. (2015). Safflower polysaccharide inhibits the proliferation and metastasis of MCF-7 breast cancer cell. Molecular Medicine Reports, 11(6), 46114616. http://dx.doi.org/10.3892/mmr.2015.3310. PMid:25673029.

McDougall, G. J., Fyffe, S., Dobson, P., \& Stewart, D. (2005). Anthocyanins from red wine-their stability under simulated gastrointestinal digestion. Phytochemistry, 66(21), 2540-2548. http://dx.doi.org/10.1016/j. phytochem.2005.09.003. PMid:16242736.

Pu, Z. J., Yue, S. J., Zhou, G. S., Yan, H., Shi, X. Q., Zhu, Z. H., Huang, S. L., Peng, G. P., Chen, Y. Y., Bai, J. Q., Wang, X. P., Su, S. L., Tang, Y. P., \& Duan, J. A. (2019). The comprehensive evaluation of safflowers in different producing areas by combined analysis of color, chemical compounds, and biological activity. Molecules, 24(18), 3381. http:// dx.doi.org/10.3390/molecules24183381. PMid:31533325.

Qazi, N., Khan, R. A., \& Rizwani, G. H. (2015). Evaluation of antianxiety and antidepressant properties of Carthamus tinctorius L. (Safflower) petal extract. Pakistan Journal of Pharmaceutical Sciences, 28(3), 991-995. PMid:26004733.

Rowell, D. R. (1996). Soil science: methods and applications. Harlow: Longman.
Sagdic, O., Ekici, L., Ozturk, I., Tekinay, T., Polat, B., Tastemur, B., Bayram, O., \& Senturk, B. (2013). Cytotoxic and bioactive properties of different color tulip flowers and degradation kinetic of tulip flower anthocyanins. Food and Chemical Toxicology, 58, 432-439. http:// dx.doi.org/10.1016/j.fct.2013.05.021. PMid:23712096.

Salem, N., Msaada, K., Elkahoui, S., Mangano, G., Azaeiz, S., Ben Slimen, I., Kefi, S., Pintore, G., Limam, F., \& Marzouk, B. (2014). Evaluation of antibacterial, antifungal, and antioxidant activities of safflower natural dyes during flowering. BioMed Research International, 2014, 762397. http://dx.doi.org/10.1155/2014/762397. PMid:25045699.

Salem, N., Msaada, K., Hamdaoui, G., Limam, F., \& Marzouk, B. (2011). Variation in phenolic composition and antioxidant activity during flower development of safflower (Carthamus tinctorius L.). Journal of Agricultural and Food Chemistry, 59(9), 4455-4463. http://dx.doi. org/10.1021/jf1049936. PMid:21434653.

Sánchez-Moreno, C. (2002). Methods used to evaluate the free radical scavenging activity in foods and biological systems. Food Science \& Technology International, 8(3), 121-137. http://dx.doi.org/10.1177/ 1082013202008003770.

Singh, R. P., Chidambara Murthy, K. N., \& Jayaprakasha, G. K. (2002). Studies on the antioxidant activity of pomegranate (Punica granatum) peel and seed extracts using in vitro models. Journal of Agricultural and Food Chemistry, 50(1), 81-86. http://dx.doi.org/10.1021/ jf010865b. PMid:11754547.

Singleton, V. L., Orthofer, R., \& Lamuela-Raventós, R. M. (1999). Analysis of total phenols and other oxidation substrates and antioxidants by means of folin-ciocalteu reagent. Methods in Enzymology, 299, 152178. http://dx.doi.org/10.1016/S0076-6879(99)99017-1.

Son, H. J., Kang, J. H., \& Song, K. B. (2017). Antimicrobial activity of safflower seed meal extract and its application as an antimicrobial agent for the inactivation of Listeria monocytogenes inoculated on fresh lettuce. Lebensmittel-Wissenschaft + Technologie, 85, 52-57. http://dx.doi.org/10.1016/j.lwt.2017.06.063.

Villa, C., Costa, J., Oliveira, M. B., \& Mafra, I. (2017). Novel quantitative real-time PCR approach to determine safflower (Carthamus tinctorius) adulteration in saffron (Crocus sativus). Food Chemistry, 229, 680-687. http://dx.doi.org/10.1016/j.foodchem.2017.02.136. PMid:28372231.

Wang, P., Liao, W., Fang, J., Liu, Q., Yao, J., Hu, M., \& Ding, K. (2014). A glucan isolated from flowers of Lonicera japonica Thunb. inhibits aggregation and neurotoxicity of A $\beta 42$. Carbohydrate Polymers, 110, 142-147. http://dx.doi.org/10.1016/j.carbpol.2014.03.060. PMid:24906740.

Wu, S., Yue, Y., Tian, H., Li, Z., Li, X., He, W., \& Ding, H. (2013). Carthamus red from Carthamus tinctorius L. exerts antioxidant and hepatoprotective effect against $\mathrm{CCl}_{4}$-induced liver damage in rats via the Nrf2 pathway. Journal of Ethnopharmacology, 148(2), 570-578. http://dx.doi.org/10.1016/j.jep.2013.04.054. PMid:23684718.

Zhang, Y., Xie, K., Liu, A., Chen, R., Chen, D., Yang, L., \& Dai, J. (2019). Enzymatic biosynthesis of benzylisoquinoline alkaloid glycosides via promiscuous glycosyltransferases from Carthamus tinctorius. Chinese Chemical Letters, 30(2), 443-446. http://dx.doi.org/10.1016/j. cclet.2018.05.010. PMid:31762583. 